\title{
Service Transformed: Illustrations of Women Veterans Past and Present
}

\author{
Monica L. Lypson, MD, MHPE, ${ }^{1-3}$ Kathryn Goldrath, ${ }^{4}$ Chiu Yueh Yao, ${ }^{5}$ and Paula T. Ross, $\mathrm{PhD}^{6}$
}

“The soldier is also a citizen.," George S. Patton, Jr.

$\mathbf{K}^{\mathrm{s}}$ EY MOMENTS OF ONE'S LIFE are often captured through photographs. The photo essay (Fig. 1) combines photographs of women veterans of different ages, race, and military backgrounds from our Service Transformed collection. The photos presented here illustrate the strong presence of women who have served in the United States. Armed Forces since the Vietnam War and the auxiliary service since the Revolutionary War. ${ }^{1}$ For each woman, the current image on the right is paired with a photograph of her former, active duty military younger self on the left. Women represent a growing veteran population with over 2.2 million women veterans in the United States. ${ }^{2}$ The photographs are intentionally juxtaposed to represent the life trajectory from past to present, youth to old age, and soldier to veteran, all of which are pertinent components of a veteran's patient history.

Viewing these images together may help healthcare providers develop an awareness of the diversity of veterans and mitigate their assumptions or biases about veteran patients. Displaying different stages of the veteran's life course-in service and as a veteran-provokes the observer to consider the importance of asking relevant questions. For women in particular, making assumptions about their military service parallels the assumptions made that cause underdiagnosis of heart disease in women. ${ }^{3}$ Healthcare providers often make clinical diagnoses or develop treatment plans based on visible characteristics or societal norms. The art of history taking may be the best defense against unconscious bias and misdiagnosis by providers.

Both the American Association of Medical Colleges and the American Association of Colleges of Osteopathic Medicine are committed to improving the healthcare of military personnel. ${ }^{4}$ While the White House's Joining Forces Initiative collectively champions the importance of obtaining a military history, medical educators must also become champions for providing the best care possible to our service members. ${ }^{5}$ As more veterans enter our facilities, healthcare providers need to ask all patients four military-specific history questions: (1) Did you, or someone close to you, serve in the military? (2) When did you serve? (3) Where did you serve? (4) What did you do in the military $?^{6,7}$ Despite what many think, fewer than $30 \%$ of veterans receive their healthcare within the Veteran Affairs (VA) health system, leaving the remaining $70 \%$ to be seen within civilian healthcare centers. ${ }^{7}$ Asking all patients about previous military service has recently gained national attention, as it helps mitigate disparities in the delivery of care and illuminate a complete narrative for this growing portion of our patient population. ${ }^{6}$

At our institution, we have incorporated these images into an interprofessional education course on veteran-centered training. One of the authors (K.G,) reflects on her reactions to the images:

As a medical student preparing for clinical rotations at the VA, I often wondered how I could empathize with my veteran patients, understanding minimally about the VA systems, military service, and unique health needs of this population. Reflecting on these images with educators and classmates in a small-group setting helped me articulate and reconcile my own unvoiced biases that I may bring into a medical encounter, opening a space for more thoughtful discussion about the medical, psychological, and social trajectory of a veteran's life. Prior to my exercise, if I had encountered some of the individuals in these photographs outside of the VA, I may not have thought to ask about a military history and may have potentially missed an important part of their patient history. The images reinforce viewers to develop a patient-centered approach in any patient interaction, understanding that there is always a story beyond what we observe.

These photographs are geared toward improving the care delivered to veterans and transforming the focus on service taken from military personnel to service delivered to them. We

Departments of ${ }^{1}$ Internal Medicine and ${ }^{2}$ Learning Health Sciences, University of Michigan Medical School, Ann Arbor, Michigan.

${ }^{3}$ VA Ann Arbor Healthcare System, Ann Arbor, Michigan.

${ }^{4}$ University of Michigan Medical School, Ann Arbor, Michigan.

${ }^{5}$ Learning Design and Publishing, Medical School Information Services, University of Michigan, Ann Arbor, Michigan.

${ }^{6}$ Office of Medical Student Education, University of Michigan Medical School, Ann Arbor, Michigan. 
FIG. 1. Portraits of United States women: During active military service (right) and now as veterans (left).

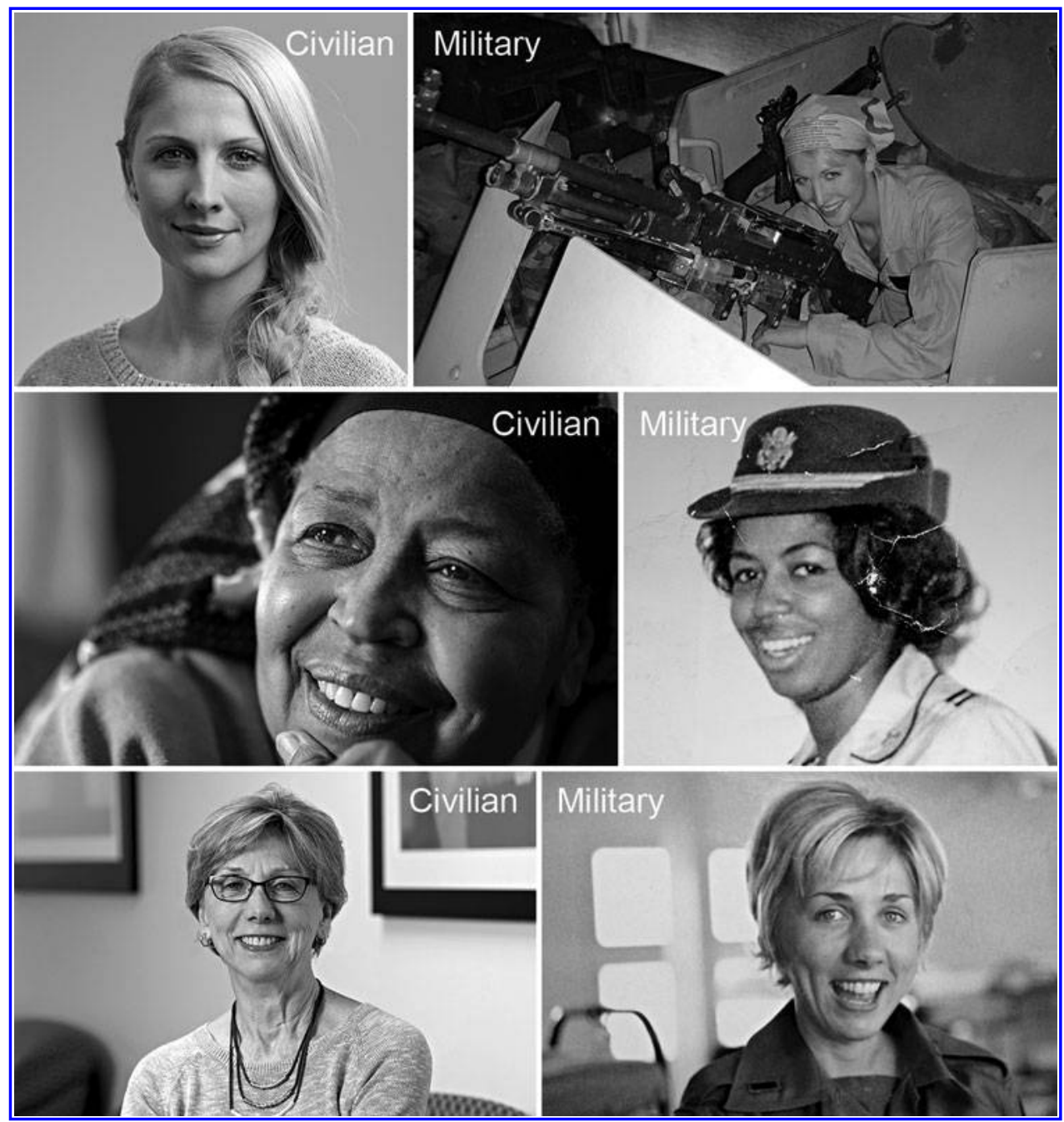

want to acknowledge and thank all veterans especially those women who committed their lives to serving our country.

\section{Author Disclosure Statement}

No competing financial interests exist.

\section{References}

1. DePauw, L.G. (1981). Women in combat: The Revolutionary War experience. Armed Forces \& Society 1981;7: 209-226.

2. National Center for Veterans Analysis and Statistics. Profile of Veterans: 2011. Data from the American Community Survey. March 2013. Available at: http://www.va.gov/vetdata/ docs/SpecialReports/Women_Veterans_2013.pdf Accessed October 14, 2015.

3. Mosca L, Jones WK, King KB, Ouyang P, Redberg RF, Hill $\mathrm{MN}$, Awareness, perception, and knowledge of heart disease risk and prevention among women in the United States Arch Fam Med 2000;9:506-515.
4. Association of American Medical Colleges (AAMC). Serving those who serve America. Joining forces: Results of an AAMC survey. Washington DC: AAMC, 2012.

5. Joining Forces. Taking action to serve America's military families. Available at: www.whitehouse.gov/joiningforces/ about Accessed August 15, 2012.

6. Brown JL. The unasked question. JAMA 2012;308:1869-1870.

7. Brown, JL, Klapholz H, Kudler H. Taking a military health history: Four critical questions. Available at: https://www .aamc.org/advocacy/campaigns_and_coalitions/360908/takinga militaryhealthhistory.html. Accessed October 14, 2015.

Address correspondence to: Monica L. Lypson, MD, MHPE Department of Internal Medicine \& Learning Health Sciences University of Michigan Medical School 2215 Fuller Road Mail Code \#14 Ann Arbor, MI 48105

E-mail:mlypson@umich.edu 